\title{
ÉMILE BENVENISTE, LEITOR DE SAUSSURE
}

\author{
Paula Ávila Nunes*
}

\begin{abstract}
RESUMO: Tendo em vista que, ao longo do Curso de Linguística Geral (CLG), encontramos uma série de instruções ao linguista, sobretudo quanto ao seu papel como teórico da linguagem, o trabalho observa como Émile Benveniste, reconhecido leitor da obra saussuriana, toma para si algumas das tarefas apresentadas no CLG. Busco, na obra benvenistiana, em suas análises e em suas exposições teórico-metodológicas, reflexos da teoria saussuriana, na tentativa de responder em que medida Benveniste executa tanto aquilo que é apenas apontado no $\mathrm{CLG}$, como o que ainda precisava ser feito em Linguística.
\end{abstract}

PALAVRAS-CHAVE: Linguística - Saussure - Benveniste - linguista

\begin{abstract}
Bearing in mind that, throughout de Saussure's Course in General Linguistics (CGL), we are able to find a series of instructions to the linguist, especially regarding his role as a language theoretician, this paper aims at observing how Émile Benveniste, a well-known reader of the saussurian works, carries out some of the tasks presented in the CGL. I search in Benveniste's work, in his analyses, theoretical and methodological expositions, reflexes of the saussurian theory, in an attempt to answer to what extent Benveniste has developed what is only pointed out in the CGL as something that still needed to be done in Linguistics.
\end{abstract}

KEYWORDS: Linguistics - Saussure - Benveniste - linguist

Benveniste é o mais saussuriano dos linguistas. Claudine Normand, em Saussure-Benveniste

\section{INTRODUÇ̃̃O}

Este é um texto cujo propósito e cujo percurso talvez causem estranheza a alguns leitores, dada sua inserção em uma forma de se pensar e estudar Linguística que ainda encontra poucos adeptos entre estudiosos fora do território francês. Prática ainda pouco explorada no Brasil, a Linguística francesa desenvolve, já há pelo menos três décadas, estudos voltados para o que se convencionou chamar de Histoire des idées linguistiques (História das idéias linguísticas), sendo a Universidade de Paris VII, inclusive, berço e local de pesquisa da Equipe d'Histoire des Theories Linguistiques (Equipe de História das Teorias Linguísticas). Mais do que oferecer ferramentas para o entendimento de teorias linguísticas vigentes, esses pensadores buscam, antes de tudo, a compreensão do processo pelo qual a Linguística se fundou como ciência e chegou a seu estado atual,

\footnotetext{
*Graduada em Letras pela Universidade Federal do Rio Grande do Sul. Doutoranda do Programa de PósGraduação em Letras na mesma universidade, com ênfase em Teorias do Texto e do Discurso. E-mail: paulaavilan@gmail.com
} 
bem como a compreensão da gênese e do desenvolvimento de teorias particulares. A obra organizada por Sylvain Auroux, publicada em 3 tomos (1989, 1992 e 2000), é, como o próprio organizador a nomeia, uma síntese tangível dos esforços desses teóricos, alguns que, inclusive, imprimem um caráter pedagógico à necessidade desse tipo de estudo das teorias linguísticas: Claudine Normand (2006a; 2009) questiona-se acerca de um ponto crucial: de que forma a história das idéias linguísticas deve ser ensinada? Essa é uma questão que deve se fazer presente para todos os linguistas, pois tem nela embutida uma outra: como ensinar Linguística?

A atenção que chamamos para essas questões não visa a propor-lhes respostas, sobretudo porque, a nosso ver, não há resposta definitiva, somente caminhos possíveis a serem propostos como alternativa. Mas uma alternativa, pouco explorada, sob nosso ponto de vista, na Linguística brasileira, reside justamente no esforço, por parte dos linguistas, em observar a trajetória de formação de um pensamento, isto é, exatamente no estudo da história das idéias linguísticas de uma teoria ou mesmo de um autor em particular. É no esteio dessa alternativa, desse tipo de fazer-pensar sobre a Linguística que implica, evidente, também um fazer-pensar sobre a linguagem -, que este texto é produzido, tendo em vista um recorte e um objetivo muito específicos: observar as influências que levaram Émile Benveniste a formular (e constantemente reformular) sua teoria enunciativa da linguagem. Dadas as proporções deste texto, as influências endereçadas são restritas apenas a uma fonte, a saber, Ferdinand de Saussure. O que segue deve dar conta de explicar o motivo de tal escolha.

Como se realiza um estudo da história das idéias linguísticas? Claudine Normand (2009), ao falar do estudo histórico em geral, parece apontar um caminho: é preciso aprender a ler, a realizar uma leitura comparativa, que, por seu turno, implica sempre comentário e análise. Tal método, se assim se pode chamar, põe em evidência dois grandes paradigmas no estudo da história de qualquer campo do saber: a "mudança na continuidade" e a "mudança na descontinuidade". A leitura que proposta a seguir da obra benvenistiana em sua relação com aquela de Saussure não escapa a esses dois grandes movimentos. Basta lembrarmos que a própria Normand considera o linguista sírio um continuador das idéias saussurianas, ainda que reconheça que, ao seguir o mestre genebrino, Benveniste chega a um outro lugar. Parece haver, portanto, a coexistência de uma mudança na continuidade que, paradoxalmente, incorpora a descontinuidade. É esse movimento de aproximação e de afastamento, de continuidade e de descontinuidade, entre os trabalhos de Saussure e Benveniste que este texto pretende analisar.

\section{BENVENISTE: UM HERDEIRO SEM TESTAMENTO}

Um texto que verse sobre Ferdinand de Saussure e Émile Benveniste, mais especificamente sobre a influência do trabalho do primeiro no trabalho do segundo, não 
deve causar surpresa, nem mesmo clamar por ineditismo. Na verdade, a relação mesmo de um teórico da Enunciação com Saussure não deve causar surpresa: a Linguística da Enunciação é, em maior ou menor grau, dependendo da teoria enunciativa em questão, tributária do pensamento saussuriano (cf. Flores \& Teixeira, 2005; Flores \& Nunes, 2007; Flores et alii, 2009). Muito já foi questionado, especulado e respondido sobre a relação dos dois linguistas. E isso porque o próprio texto benvenistiano permite-nos indagar o lugar que o pensamento de Saussure tem em seu trabalho. Não são raras as referências ao genebrino nos Problemas de Linguística Geral I e II (doravante PLG I e PLG II, respectivamente). Algumas delas, bastante emocionadas, resumem: todo o linguista, seja ele qual for, deve algo a Saussure. E Benveniste, obviamente, não está imune a isso.

Há quem diga que Benveniste é um continuador de Saussure. Outros, que ele vai além, sobretudo baseados em sua célebre asserção: "compete-nos tentar ir além do ponto a que Saussure chegou na análise da língua como sistema significante" (PLG II, p. 224). E esse "ir além" foi explicado de várias formas: Benveniste vai além porque contempla o que "sobrara" do Curso de Linguística Geral (CLG), a saber, e principalmente, a noção de sujeito; vai além porque abre a Linguística a outras ciências humanas; vai além porque passa a interrogar a língua do ponto de vista do sentido:

Aqui Benveniste separa-se, sem o declarar, de Saussure. Ele nos diz que se trata somente de "ir além" no estudo da significação; na realidade, pode-se pensar que ele vai a outro lugar: retorno a uma fenomenologia que um estruturalismo metodológico não tinha recoberto, abertura para descrições integrando traços da subjetividade nos enunciados e sua presença ativa em toda enunciação. Nunca abandonar a língua, na sua matéria significante, em suas estruturas comuns, no seu aparelho "semiótico", mas conciliar esse gesto saussuriano com a singularidade subjetiva, com a comunicação sempre situada, com o "acontecimento inebriante" que é todo enunciado. Analisar "o semântico": eis a aposta de Benveniste (NORMAND, 2006a:77¹).

Enfim, as razões são várias. Este texto não tem a pretensão de discutir detidamente em que medida Benveniste é um continuador do trabalho saussuriano ou se vai além dele, uma vez que ambas as hipóteses que já foram discutidas por outros teóricos. Antes, partindo da idéia de que Benveniste é, ao mesmo tempo, um continuador que chega a outro lugar, meu objetivo parte de uma só questão: continuando ou ultrapassando o trabalho do mestre de Genebra, o que temos plena certeza é de que Benveniste foi um exímio leitor de Saussure. Mesmo Simon Bouquet, crítico feroz de algumas passagens do trabalho benvenistiano" ${ }^{2}$, reconhece: "Benveniste (...), mesmo sem ter lido os textos originais saussurianos, é um intérprete fiel do pensamento do linguista genebrino" (2000:268). Dessa forma, interessa responder: o que faz de Benveniste um leitor tão bom do material de Saussure? Seria apenas a

\footnotetext{
${ }^{1}$ As traduções do texto de Normand são de Carmen Nassar, publicadas na Revista Letras (cf. bibliografia).

${ }^{2}$ Sua crítica repousa sobre o texto de Benveniste intitulado Natureza do signo linguístico, publicado no PLG I. Sobre isso, ler Bouquet (2000).
} 
influência de Antoine Meillet, aluno de Saussure e mestre de Benveniste? E, mais importante: como os reflexos do pensamento saussuriano se inscrevem na obra de Benveniste, mais precisamente nos PLG I e II?

Para tanto, propomos uma trajetória a ser perseguida: se Benveniste afirma que é preciso ir além do ponto que Saussure deixou ${ }^{3}$, resta-nos analisar qual é esse ponto. Logo após, procuramos, então, observar como Benveniste dá continuidade ao trabalho saussuriano, o que, de nossa parte, acreditamos estar diretamente ligado às observações contidas no $C L G$ em referência ao trabalho que cabe aos linguistas.

\section{O PONTO EM QUE SAUSSURE PAROU}

Talvez entre algumas das passagens mais citadas de Émile Benveniste estejam aquelas que se reportam a uma ultrapassagem a Saussure. Em ordem cronológica, temos essa idéia no texto A forma e o sentido na linguagem, de 1966, e, novamente, no texto Semiologia da Língua, publicado 3 anos mais tarde. Vejamos em que contextos se dão tais ocorrências:

A semiologia da língua foi bloqueada, paradoxalmente, pelo instrumento mesmo que a criou: o signo. Não se poderia descartar a idéia do signo linguística sem suprimir o caráter mais importante da língua; não se poderia estendê-lo ao discurso inteiro sem contradizer sua definição como unidade mínima. Em conclusão, é necessário ultrapassar a noção saussuriana do signo como princípio único, do qual dependeria simultaneamente a estrutura e o funcionamento da língua. Essa ultrapassagem far-se-á por duas vias: na análise intralinguística (...) e na análise translinguística dos textos, das obras (...) (1989:67).

É a noção de signo que, doravante, integra no estudo da língua a noção muito geral de significação. Esta definição a coloca exatamente, inteiramente? Quando Saussure introduziu a idéia de signo linguístico, ele pensava ter dito tudo sobre a natureza da língua; não parece ter visto que ela podia ser outra coisa ao mesmo tempo, exceto no quadro da oposição bem conhecida que ele estabelece entre língua e fala. Compete-nos tentar ir além do ponto a que Saussure chegou na análise da língua como sistema significante. É necessário, de início, compreender tudo o que implica em relação às noções de que nos ocupamos aqui - a noção de sentido e a noção de forma - a doutrina saussuriana de signo (ib., p. 224).

A transcrição dessas longas passagens deixa evidente que, ao se referir a "ultrapassar" Saussure, ir além dele, Benveniste refere-se unicamente à idéia de signo. Obviamente, por ser uma noção central em Linguística, uma reconsideração no estatuto de signo promove alterações substanciais no próprio fazer linguístico, motivo pelo qual

\footnotetext{
${ }^{3} \mathrm{Ou}$, mais precisamente, "do ponto em que Saussure parou", conforme o original em francês: "du point où Saussure s'est arrêté” (Benveniste, 1974:219).
} 
a teoria benvenistiana acaba por chegar a outro lugar. Mas é preciso que se sublinhe: Benveniste pretende ir além do genebrino naquilo que toca à noção de signo, mesmo que, nessa empreitada, chegue a uma teoria que enfatize muito mais o sujeito na linguagem do que as questões que envolvem, de forma mais restrita, questões relacionadas ao signo linguístico.

E como essa "ultrapassagem" é feita? Proponho a leitura de outra passagem que parece lançar luz sobre a questão. Em um texto de 1954, Tendências recentes em linguística geral, Benveniste estipula: "enquanto dantes a objetividade consistia na aceitação integral dos dados (...), hoje nos prendemos mais à identificação dos elementos na medida em que são distintivos em todos os níveis de análise” (p. 9). Se nossa leitura de Benveniste estiver correta, notamos aí o germe do que viria a ser devidamente desenvolvido em Semiologia da Língua (1969), em A forma e o sentido na linguagem (1966) e em Os níveis de análise linguística (1964). Isto é, enquanto ele reconhece que o axioma saussuriano de que "na língua só existem diferenças" (cf. CLG, p. 139) governa toda a linguística, Benveniste já idealiza que tal configuração precisa ser expandida a todos os níveis linguísticos. Tal expansão só parece ter sido devidamente teorizada pelo linguista alguns anos mais tarde, nos textos da década de 60. Acreditamos que seja aí que Benveniste estenda a noção de signo "ao discurso inteiro sem contradizer sua definição como unidade mínima” (cf. Benveniste, 1989, p. 67).

No entanto, se esta é uma interpretação válida, ela não traz muitas novidades quanto à relação Saussure-Benveniste. Portanto, é na tentativa de observar como Benveniste retoma o trabalho de Saussure que gostaria, aqui, de lançar uma nova hipótese: a continuidade de Benveniste, ainda que declaradamente ligada à noção de signo linguístico, pode ser flexibilizada, estendida a toda a obra do linguista sírio. E, para desenvolver tal teoria, é preciso observar o texto saussuriano no que ele deixa para o futuro, o que, como já foi defendido em outro trabalho (Nunes, 2011), parece estar nas "instruções" saussurianas ao linguista. Em resumo, nossa hipótese vem a ser: Benveniste vai além de Saussure pois toma para si a tarefa de desenvolver em Linguística aquilo que é apenas lançado como proposta futura no CLG, dado que Saussure, ele próprio, não poderia executá-la, uma vez que as questões de Linguística Geral ainda precisavam ser endereçadas antes de qualquer outra coisa. Tentamos mostrar, a seguir, como vemos esse percurso na obra benvenistiana.

\section{A LEITURA BENVENISTIANA DO CURSO DE LINGUÍSTICA GERAL}

Para os propósitos deste artigo, seria interessante começar por comprovar indícios da leitura de Saussure por parte de Benveniste e como essa leitura se manifesta em sua obra. Partimos, nesse início, de exemplos bem simples, que atestam diretamente a influência saussuriana. Para isso, reproduzem-se abaixo algumas passagens dos textos 
que compõem as seções intituladas Transformações da Linguística, contidas nos PLGs $I$ e II. Isso porque é nessas duas seções que Benveniste é convocado a falar sobre Saussure e a explicitar aspectos de sua teoria. Acreditamos que seja possível, portanto, observar os ecos do pensamento do genebrino mesmo em um corpus tão pequeno, se comparado a toda obra benvenistiana. Apenas a título de exemplo, observemos o que ambos os autores dizem sobre um aspecto central na Linguística: sua matéria e seu objeto. Comparemos as seguintes passagens, de Saussure, à esquerda, e de Benveniste, à direita:

Quadro 1 - Comparação de passagens do $C L G$ e dos $P L G S$

A matéria da Linguística é constituída G.D. - Em que a linguística se distingue inicialmente por todas as manifestações da linguagem humana (...). Isso não é tudo: como a linguagem escapa as mais das vezes à observação, o linguista deverá ter em conta os textos escritos, pois somente eles lhe farão conhecer os idiomas passados ou distantes $(C L G, \mathrm{p}$. 13) das antigas ciências da linguagem, como, por exemplo, a gramática, a filologia ou a fonética?

E.B. - A linguística pretende englobar tudo isto e o transcender. Tudo o que diz respeito à linguagem é objeto da linguística. (...) A linguística se ocupa do fenômeno que constitui a linguagem e, naturalmente, sem negligenciar a parte da linguagem que se transforma em escrita (PLG II, p. 29).

Outras ciências trabalham com objetos dados previamente e que se podem considerar, em seguida, de vários pontos de vista; em nosso campo, nada de semelhante ocorre (CLG, p. 15).

Destarte, qualquer que seja o lado por que se aborda a questão, em nenhuma parte se nos oferece integral o objeto da Linguística. Sempre encontramos o dilema: ou nos aplicamos a um lado apenas de cada problema e nos arriscamos a não perceber as dualidades assinaladas acima, ou, se estudarmos a linguagem sob vários aspectos ao mesmo tempo, o objeto da linguística nos
Não há nada de substancial na linguagem. Todas as ciências da natureza encontram seu objeto constituído. A linguística, e é isto que a diferencia de qualquer outra disciplina científica, se ocupa de algo que não é objeto, não é substância, mas que é forma (PLG II, p. 31 - grifo no original) Comecemos por observar que a linguística tem duplo objeto: é a ciência da linguagem e ciências das línguas. Essa distinção, que nem sempre se faz, é necessária: a linguagem, faculdade humana, característica universal e imutável do homem, não é a mesma coisa que as línguas, sempre particulares e variáveis, nas quais se realiza. É das línguas que se ocupa o linguista e a 


\begin{tabular}{l|l}
\hline aparecerá como um aglomerado confuso & linguística é em primeiro lugar a teoria \\
de coisas heteróclitas, sem liame entre si & das línguas $(P L G I$, p. 20) \\
$(C L G$, p. 16$)$ & \\
\hline
\end{tabular}

É provável que os excertos acima deixem claras as semelhanças entre os dois. Semelhanças que obviamente não são fortuitas, ou fruto de coincidência: Benveniste lê Saussure e, mais do que isso, os pressupostos elaborados pelo mestre são norteadores na obra benvenistiana. Não é à toa que, como afirma Normand (2006a), as análises de Benveniste sejam "perfeitamente saussurianas" (p. 76). Cabe aqui, portanto, um exemplo dessas análises. Em Semiologia da língua, diz Benveniste:

Para que um signo exista, é suficiente e necessário que ele seja aceito e que se relacione de uma maneira ou de outra com os demais signos. A entidade considerada significa? A resposta é sim, ou não. (...) "Chapéu" existe? Sim. "Chaméu” existe? Não. A questão não é mais definir o sentido, enquanto o que releva da ordem semiótica. No plano do significado, o critério é: isto significa ou não? Significar é ter um sentido, nada mais. E este sim ou não só pode ser pronunciado por aqueles que manuseiam a língua, aqueles para os quais esta língua é a língua e nada mais. (...) É no uso da língua que um signo tem existência; o que não é usado não é signo; e fora do uso o signo não existe ( $P L G I I$, p.227).

Ora, essa análise encontra um correlato muito parecido no $C L G$, em que lemos:

Seja em francês sižlaprã: poderei cortar esta sequência após $l$ e tomar sižl como unidade? Não: basta considerar os conceitos para ver que essa divisão é falsa. A separação em sílabas siž-l-aprã nada tem tampouco de linguístico, a priori. As únicas divisões possíveis são: $1^{\circ}$ si-ž-la-prã ("si je la prends"), e $2^{\circ}$ si-ž-l-aprã ("si je l'apprends"), e são determinadas pelo sentido que se dê a essas palavras (p. 121 - grifos no original).

No entanto, se o trabalho de Benveniste é de inegável inspiração saussuriana, ele não se resume a isso. Em que o trabalho de um se diferencia do de outro? A resposta é simples, mas precisa ser desenvolvida em todas as direções: Saussure, como diz o próprio Benveniste, é o homem dos princípios. Benveniste é o homem que aplica esses princípios. Nas palavras de Normand (2006a):

Saussure deu os princípios, os temas, o método; Benveniste o aplicou em suas análises concretas que radicalmente transformaram (ou simplesmente enriqueceram) as descrições comparatistas. Benveniste é o mais saussuriano dos linguistas, ele permitiu resgatar, a partir de Saussure, uma linguística da significação (ib., p. 71).

A parte final do comentário de Normand é crucial para entendermos um ponto: tomando por verdadeira a asserção de que Benveniste instaura uma linguística diferente, ela só é diferente e possível por causa de Saussure, porque é da obra do genebrino que ele resgata, através de sua leitura perspicaz, aquilo que o $C L G$ apenas lança como 
proposta futura para a Linguística. E é nesse ponto que propomos que analisemos a obra de Benveniste.

\section{O LINGUISTA: PONTO DE TOQUE DE SAUSSURE E BENVENISTE}

Em Nunes (2011), foi defendido o ponto de vista que institui que a possibilidade de uma nova Linguística, a partir de Saussure, dá-se não pelo trabalho do mestre como linguista, mas pela possibilidade que ele lança ao futuro, a ser desempenhada pelos futuros linguistas. Retomando as palavras utilizadas outrora:

\footnotetext{
Vemos, assim, que o que há de "novo" no $C L G$ não é propriamente o que ele realiza, enquanto obra fundadora, mas o que ele possibilita para o futuro, para os linguistas que, a partir dali, tomaram os ensinamentos saussurianos como base para uma nova Linguística, que se dá, na verdade, $a$ posteriori. O ineditismo e a virtude de Saussure, incomparáveis e singulares, estão em tornar isso possível: diferentemente dos outros, Saussure preocupou-se com os fundamentos, e isso o levou não a ensinar Linguística Geral apenas, mas, sobretudo, a ensinar ao linguista o que ele faz (Nunes, op. cit, p. 8).
}

Partindo desse ponto de vista, podemos, então, observar como Benveniste realiza algumas tarefas apontadas por Saussure como pertinentes ao linguista. Vejamos algumas delas em cada uma das seções a seguir.

\section{O LUGAR DA LÍNGUA DENTRE OS FATOS SEMIOLÓGICOS}

O CLG propõe à página 24: "cabe ao psicólogo determinar o lugar exato da Semiologia; a tarefa do linguista é definir o que faz da língua um sistema especial no conjunto dos fatos semiológicos". Essa tematização sobre o lugar da língua dentre os fatos semiológicos é retomada por Benveniste em seu artigo Semiologia da língua. Nele, temos claramente uma remissão a Saussure no parágrafo de abertura, em que Benveniste se questiona, recuperando a idéia do genebrino e de Peirce: "qual é o lugar da língua entre os sistemas de signos" (1989:63)? Essa será a pergunta a ser respondida no artigo, na tentativa de dirimir um impasse aberto pelo $C L G$ : se a Linguística só pode se definir em relação à Semiologia, e esta não existe ainda, como então defini-la? Nas palavras de Benveniste, "Saussure devolve à ciência futura o papel de definir o próprio signo" (ib., p. 49).

A resposta benvenistiana é precisamente a realização do que Saussure desejava: determinar o lugar exato da semiologia e da língua em relação a ela. Para isso, lemos em Semiologia da língua: "o caráter comum a todos os sistemas e o critério de sua ligação à semiologia é sua propriedade de significar ou SIGNIFICÂNCIA, e sua composição em unidades de significância, ou SIGNOS. Trata-se agora de descrever seus caracteres 
distintivos" (p. 52 - destaques no original). E, ao fazer isso, o linguista singulariza o lugar da língua: "é que a língua ocupa uma situação particular no universo dos sistemas de signos" (p. 55) porque ela "é o interpretante de todos os outros sistemas, linguísticos e não-linguísticos" (p. 61). Além disso, "a língua é o único sistema em que a significação se articula em duas dimensões" (p. 66): a semiótica e a semântica. O que diferencia a língua é, portanto, seu privilégio de "comportar simultaneamente a significância dos signos e a significância da enunciação" (idem).

\section{RELAÇÕES ENTRE A LÍNGUA LITERÁRIA E A LÍNGUA CORRENTE}

De acordo com a proposta do $C L G$, “(...) o linguista deve também examinar as relações recíprocas entre a língua literária e a língua corrente (...)” (p. 30). Ainda que essa não seja uma idéia desenvolvida substancialmente por nenhum dos dois linguistas, Benveniste a tangencia em seu texto As relações de tempo no verbo francês (1959). Segundo o autor, é necessário fazer uma distinção entre dois planos de enunciação: o da história e o do discurso. E adverte: "a distinção que fazemos entre narrativa histórica e discurso não coincide, portanto, absolutamente, com a distinção entre língua escrita e língua falada. A enunciação histórica é reservada hoje à língua escrita. O discurso, porém, é tanto escrito como falado" (p. 267 - grifos meus). Para fins de análise, Benveniste lança mão, inclusive, da análise de dois tipos de texto ${ }^{4}$ - um científico, escrito por um historiador, e outro de ficção - incorporando ao corpus de análise também o texto literário.

Em A linguagem e a experiência humana (1965), em que Benveniste traça distinções entre o tempo físico, o tempo crônico e o tempo linguístico, há uma breve referência à escrita, próxima àquela de seu texto sobre as relações de tempo no verbo francês. Afirma ele: "o escritor tira partido instintivamente desta diferença [entre passado definido e indefinido] para separar o plano da história e da narração" (1995:76). A explicação para isso pode estar no texto anterior, no qual nos explica que, "na prática, passa-se de um ao outro [do plano da narrativa histórica ao plano do discurso] instantaneamente. (...) $\mathrm{O}$ próprio da linguagem consiste em permitir essas transferências instantâneas" (1989:267).

Temos, assim, pelo menos em dois dos textos que compõem os $P L G \mathrm{~s}$, não só referência à língua literária como também uma análise de texto literário. É interessante notar, contudo, que estamos referindo à linguagem literária como algo diferente de linguagem poética ${ }^{5}$. Sobre esta última, ainda que Benveniste reconheça sua importância

\footnotetext{
${ }^{4}$ Talvez este seja também um exemplo de como Benveniste pratica uma outra diretriz saussuriana: "o linguista deverá ter em conta os textos escritos" (p. 13).

${ }^{5}$ Em A forma e o sentido na linguagem (1966), Benveniste diferencia radicalmente o estudo da linguagem ordinária daquele dedicado à linguagem poética: "nosso domínio será a linguagem dita ordinária, a linguagem comum, com exclusão expressa da linguagem poética, que tem suas próprias leis e suas funções próprias" (p. 221). No entanto, o teórico nunca chegou a desenvolver, em nenhum dos textos que compõem os $P L G \mathrm{~s}$, que leis e funções seriam
} 
dentro da Linguística, não podemos afirmar que haja uma posição do linguista frente a isso. Em resposta a pergunta "a linguagem poética tem interesse para a linguística?", feita por Guy Dumur em entrevista reproduzida em Esta linguagem que faz história (1968), Benveniste responde: "Imensamente. Mas este trabalho apenas começou. Não se pode dizer que o objeto de estudo, o método a ser empregado já estejam claramente definidos. Há tentativas interessantes, mas que mostram a dificuldade de se abandonarem categorias utilizadas para a análise da linguagem ordinária” (p. 37) ${ }^{6}$

No entanto, se os PLGs apenas tangenciam o assunto, os manuscritos benvenistianos, descobertos recentemente, vão em direção exatamente oposta. Mais de 400 páginas formam um dossiê de manuscritos sobre a linguagem poética, que estão sendo progressivamente analisados e publicados, principalmente pela pesquisadora Chloé Laplantine. A última publicação desses manuscritos, datada de 2011, intitulada Baudelaire, apresenta 770 páginas, editadas e transcritas pela estudiosa, de análises e considerações do linguista sírio acerca do trabalho baudelairiano.

\section{CONHECIMENTO DE VÁRIAS LÍNGUAS}

Esse tópico dispensaria quaisquer comentários se não fosse pelo caráter de curiosidade que permite suscitar. Segundo o $C L G$, “(...) o que nos é dado são as línguas. O linguista está obrigado a conhecer o maior número possível delas para tirar, por observação e comparação, o que nelas exista de universal"' (p. 33).

Benveniste, tal como Saussure, era um exímio conhecedor de línguas. Barthes (2004), em sua resenha por ocasião do lançamento do PLG II, reflete que Benveniste "é um linguista das línguas, e não apenas um linguista da linguagem" (p. 241 - grifo no original). Além do Vocabulário das instituições indo-européias, em que Benveniste demonstra todo seu conhecimento em linguística comparada, os próprios $P L G$ s nos dão uma amostra da capacidade desse linguista: são mais de 50 línguas citadas em seus exemplos e análises.

Um dos textos mais interessantes para se observar a dimensão do conhecimento benvenistiano sobre diversos idiomas é o seu célebre Estrutura das relações de pessoa no verbo, em que mais de 20 línguas são citadas para defender seu ponto de vista. Apenas na página 251, temos evidências apresentadas em 9 línguas diferentes, e apenas para duas delas Benveniste recorre a exemplos analisados por outros autores ${ }^{7}$.

próprias a esse tipo de linguagem.

${ }^{6}$ Quem parece ter levado o empreendimento saussuriano até o fim é Jakobson. Sobre isso, ver, por exemplo, seu texto Linguística e poética, publicado em Linguística e comunicação (cf. bibliografia).

${ }^{7}$ É preciso observar que muitas das línguas utilizadas por Benveniste em seus exemplos provêm de análises de outros linguistas, tais como Sapir, para línguas ameríndias, e de Jakobson, para as de origem eslava. Isso não reduz, contudo, a imensa capacidade de Benveniste de se aproveitar de descrições realizadas por esses linguistas e delas se apropriar de forma a usá-las para seus propósitos de exemplificação. 


\section{O LUGAR DA LINGUÍSTICA DENTRE AS CIÊNCIAS HUMANAS}

Mais um ponto de convergência entre Saussure e Benveniste se dá no que tange ao lugar da Linguística entre as ciências humanas. Ainda que o primeiro tenha feito um esforço para distinguir e situar a Linguística longe de outras ciências humanas, movimento diametralmente oposto ao de Benveniste, vemos uma preocupação em estabelecer a pertinência dessa ciência em relação à cultura e à sociedade:

Qual é, enfim, a utilidade da Linguística? Bem poucas pessoas têm a respeito idéias claras. (...) Mas é evidente, por exemplo, que as questões linguísticas interessam a todos - historiadores, filólogos, etc. - que tenham que manejar textos. Mais evidente ainda é a sua importância para a cultura geral: na vida dos indivíduos e das sociedades, a linguagem constitui fator mais importante que qualquer outro. Seria inadmissível que seu estudo se tornasse exclusivo de alguns especialistas (p. 14).

No entanto, temos a advertência: por ser tomada como objeto de estudo por tantos especialistas diferentes, algumas idéias "absurdas, preconceitos, miragens, ficções" (idem) sobre a Linguística e sua relação com o indivíduo e sociedade germinaram. "A tarefa do linguista, porém, é, antes de tudo, denunciá-los e dissipá-los tão completamente quanto possível" (idem).

Benveniste, pondera Normand (2006a), abre a Linguística a outros caminhos:

A ciência progride, o conhecimento da linguagem abre sem cessar novos caminhos, nada pode impedir seu desenvolvimento: "semiologia geral", "semiologia de segunda geração", "semiologia universal"... Todas as ciências estão envolvidas, convidadas a se reagruparem sob a égide de um pensamento sobre os signos que lhes impõem uma coisa: não esquecer que o sentido passa sempre pelas formas (p. 77).

Roland Barthes (op. cit.) também pontua a abertura que o pensamento benvenistiano propõe em relação a Saussure: "Benveniste - e aí está seu êxito - toma a linguagem nesse nível decisivo em que, sem deixar de ser plenamente linguagem, recolhe tudo aquilo que estávamos habituados a considerar exterior ou anterior a ela" ( $\mathrm{p}$. 209). Em Vista d'olhos sobre o desenvolvimento da linguística, Benveniste esclarece:

Tem-se a impressão de que, para os linguistas de hoje, os fatos da linguagem se transmudam em abstrações, (...) e de que a linguística se afasta das realidades da linguagem e se isola das outras ciências humanas. Ora, é exatamente o contrário. Comprova-se, ao mesmo tempo, que esses métodos novos da linguística assumem o valor de exemplo e mesmo de modelo para outras disciplinas, que os problemas da linguagem interessam agora a especialidades muito diversas e cada vez mais numerosas e que uma corrente de pesquisas leva as ciências do homem a trabalhar dentro do mesmo espírito que anima os linguistas (1995: 19-20). 
Benveniste tem, portanto, plena consciência da potencialidade da Linguística e de seu papel como "ciência piloto" (cf. Dosse, 2007). É a partir disso que ele se permite refletir sobre a linguagem a partir de um outro ponto de vista. E faz isso ao considerá-la no que ela tem de mais importante: ser um fato humano.

(...) a linguagem é também um fato humano; é, no homem, o ponto de interação da vida mental e da vida cultural e ao mesmo tempo o instrumento dessa interação. Uma outra linguística poderia estabelecer-se sobre os termos desse trinômio: língua, cultura, personalidade (1995: 17).

É a partir daí, da consideração da Linguística como a ciência que, por tratar da linguagem trata também do homem, que Benveniste deu aos linguistas "a subjetividade, o mundo e o discurso que o contém; reatou com a filosofia, encontrou a psicologia social e a pragmática; reencontrou a virtude do diálogo e da interação" (Normand, op. cit., p. 71).

\section{CONSIDERAÇÕES FINAIS}

Este texto tentou traçar evidências que não só comprovassem, como já foi feito por outros autores, o elo que une Benveniste a Saussure, mas, sobretudo, que demonstrassem de que natureza é esse elo. A leitura, conforme proposta aqui, do $C L G \mathrm{e}$ de alguns textos que compõem o PLG $I$ e $I I$ teve por objetivo precisar que o ponto que parece unir os dois estudiosos está precisamente na concepção do que vem a ser o ofício do linguista, lançada como perspectiva futura no $C L G$ (cf. Nunes, 2011). Se, como Benveniste mesmo aponta, a principal tarefa de Saussure era ensinar aos linguistas da época em que constituía o seu trabalho, Benveniste parece ter aprendido bem as lições do mestre, e tomado para si a tarefa de realizar o que outrora só ficara indicado no CLG. E isso não é fortuito: cabe lembrar que Benveniste segue "uma formação de linguística na filiação duplamente comparatista e saussuriana de Antoine Meillet" (Dosse, 2007:63). Não é de surpreender, portanto, que toda a obra benvenistiana seja de inspiração saussuriana.

Isso não quer dizer, de forma alguma, que todo o trabalho de Benveniste possa ser reduzido ao de Saussure, pois, conforme antecipado na introdução deste trabalho, Benveniste é um continuador de Saussure, mas também um "descontinuador", uma vez que chega a um outro lugar. Há extrema originalidade e autoria no trabalho benvenistiano: "o lugar de Benveniste no concerto dos grandes linguistas que marcam com a sua influência todo o trabalho intelectual da nossa época é totalmente original - a ponto de ser, por vezes, parece-me, subestimado" (Barthes, op.cit: p. 240).

Se os fundamentos da teoria benvenistiana estão em Saussure, isso em nada reduz seu brilhantismo em aplicá-los de forma coerente e inovadora, sobretudo porque, como afirma Bouquet (op. cit.), Benveniste nunca teve acesso aos manuscritos saussurianos. 
Todas as suas interpretações das palavras do mestre, que posteriormente vieram a ser comprovadas pela descoberta dos manuscritos, foram elaboradas exclusivamente com base no $C L G$, o que, sabemos, é uma visão fragmentada e ecoada das idéias "originais" de Saussure.

O mérito de Benveniste, além de ter sido um linguista de uma envergadura a que poucos se assemelham, está na sua habilidade em ter capturado o cerne do pensamento saussuriano em meio ao turbilhão de idéias esparsas em que se constitui o Curso e aplicá-las de forma primorosa em suas dezenas de artigos que mudaram o cenário da linguística francesa. É por essa perspectiva que, como ele próprio diz, Saussure cumpriu bem seu destino, sendo efetivamente um mestre que permitiu que outros linguistas, incluindo Benveniste, ganhassem um lugar próprio de enunciação. É assim que a vida de Saussure "se confunde para sempre com a nossa" (Benveniste, 1995:49).

\section{REFERÊNCIAS BIBLIOGRÁFICAS}

AUROUX, Sylvain. (Org.) Histoire des idées linguistiques. Tome 1. (Philosophie et langage). Bruxelles, Pierre Mardaga, 1989.

BARTHES, Roland. O rumor da língua. São Paulo: Martins Fontes, 2004.

BENVENISTE, É. Problemas de Linguística Geral I. São Paulo: Pontes, 1995. . Problemas de Linguística Geral II. São Paulo: Pontes, 1989.

Problèmes de linguistique générale II. Paris: Gallimard, 1974.

BOUQUET, Simon. Introdução à leitura de Saussure. São Paulo: Cultrix, 2000.

DOSSE, François. História do Estruturalismo. V.1: O campo do signo. Bauru: EDUSC, 2007.

FLORES, Valdir do Nascimento; TEIXEIRA, Marlene. Introdução à Linguistica da

Enunciação. São Paulo: Contexto, 2005.

FLORES, Valdir do Nascimento et alii. Dicionário de Linguística da Enunciação. São Paulo:

Contexto, 2009.

FLORES, Valdir do Nascimento; NUNES, Paula Ávila. Linguística da enunciação: uma herança saussuriana? In: Organon (UFRGS), v. 21, p. 199-209, 2007.

JAKOBSON, Roman. Linguistica e comunicação. São Paulo: Cultrix, 2005.

NORMAND, Claudine. Allegro ma non troppo: invitation à la linguistique. Paris : Ophrys, 2006a.

. Saussure-Benveniste. In: Revista Letras: Émile Benveniste - interfaces Enunciação \& Discursos. Santa Maria: UFSM, n.33, 2006b.

. Comment faire l'histoire de la linguistique? Cahiers de l'ILSL. n²6. 2009.

NUNES, Paula Ávila. Ferdinand de Saussure e o Curso de Linguística Geral: que Linguística?

Linguasagem. 2011. Disponível em:

http://www.letras.ufscar.br/linguasagem/edicao17/art nunes.php. Acesso em 20/10/11.

SAUSSURE, Ferdinand de. Curso de Linguística Geral. 26a ed. São Paulo: Cultrix, 2004. 